\title{
InPEX OF APVERTISERS
}

4pi Analysis, Inc (www.4pi.com)

Advanced Microscopy Techniques (www.amtimaging.com)

Ångstrom Scientific Co (www.angstrom.us)

BIBST Labs (www.bibst.com)

Bruker AXS Microanalysis (www.bruker-axs.com

Carl Zeiss SMT, Inc. (smt.zeiss.com)

McCrone Group (www.collegeofmicroscopy.com)

Diatome (www.emsdiasum.com)

Electron Microscopy Sciences (www.emsdiasum.com)

Ernest F. Fullam (www.fullam.com)

Evex Analytical (www.evex.com)

FEI Company (www.feic.com)

Gatan Inc. (www.gatan.com)

Geller MicroAnalytical Lab (www.gellermicro.com)

Hitachi High Technologies America (www.hitachi-hhta.com)

IXRF Systems (www.ixrfsystems.com)

JEOL USA (www.jeol.com)

Lehigh University (www.lehigh.edu/microscopy)
45 M.E. Taylor Engineering (www.semsupplies.com)

19 Materials Analytical Services (MAS) (www.mastest.com)

21 McCrone Research Institute (www.mcri.org)

65 minus k TECHNOLOGY (www.minusk.com)

Olympus Soft Imaging Solutions Corp (www.soft-imaging.net) ........... 37

Omniprobe, Inc. (www.omniprobe.com) .............................................. 9

Oxford Instruments (www.oxford-instruments.com) .............................. 7

Scientific Instruments and Applications (www.sia-cam.com) ............... 49

SEMTech Solutions (www.semtechsolutions.com) .................................. 35

SII NanoTechnology USA Inc. (www.siintusa.com) ................................ 25

SIMPore, Div. TEMwindows (www.TEMwindows.com) ....................... 61

Ted Pella, Inc. (www.tedpella.com) ...........................................21, 39, 49

Tescan USA (www.tescan-usa.com) ........................................................ 53

Thermo Scientific (Part of Thermo Fisher Scientific) (www.thermo.com) ....... 15

Marine Biological Laboratory (www.mbl.edu/education) ........................6 65

XEI Scientific (evactron.com) ................................................................ 33

Employment Ads

33 Louisiana State University (cthomps@lsu.edu).....

37

9

(1)

\section{SUBSORIPTION REQUESTS/OHANGES}

\section{Individuals requesting subscriptions, or wishing to change/correct their current address, are requested to do so via our www site: \\ http://www.microscopy-today.com SUBSCRIPTION POLICIES}

- Microscopists in Canada, Mexico, and the United States of America are eligible for free subscriptions.

- Microscopy Society of America members receive Microscopy Today as a free member benefit anywhere in the world.

- Non-MSA members, outside North America, may subscribe for $\$ 60$ US per year to cover postage and handling.

- Scanned back issues of MT are available for low-resolution free download on our www site above, after a six-month delay. The entire issues are downloaded-advertisements and all.

- High resolution, CD format, complete volumes are available via airmail for the prices listed below. Note that a volume contains 6 issue for 2002 onwards and 10 issues for 1992 to 2001. Contact editor to order.

Preferred payment is via credit card information when subscribing at the www address. Bank transfer information available from the editor. Checks in US\$, payable to "Microscopy Today," to the editor.

\begin{tabular}{|c|c|c|c|}
\hline & \multicolumn{3}{|c|}{ Products } \\
\hline Subscription Schedule & $\begin{array}{l}\text { Current Printed } \\
\text { Issue }\end{array}$ & $\begin{array}{l}\text { Back Issue } \\
\text { Downloaded After } \\
\text { 6-Month Delay }\end{array}$ & $\begin{array}{l}\text { Back Issue Volume } \\
\text { High Resolution CD }\end{array}$ \\
\hline Anyone in North America & Free & Free Low Resolution & $\begin{array}{l}\text { MSA member } \$ 30 / \text { volume } \\
\text { Non-MSA mbr. } \$ 45 / \text { volume }\end{array}$ \\
\hline MSA member outside North America & Free & Free Low Resolution & $\$ 45 /$ volume \\
\hline Non-MSA member, outside North America & $\$ 60$ /year (6 issues) & Free Low Resolution & $\$ 60 /$ volume \\
\hline
\end{tabular}

